\title{
Yerelleştirme Olgusu ve Sürecinde Çevirinin Anthony Pym Açısından İşleyişi ve Yeri
}

\author{
Başak Pırıl Gökayaz (D), İzmir - Faruk Yücel (i), İzmir \\ https://dx.doi.org/10.37583/diyalog.958527
}

$\ddot{O} z$

1970'li yıllarda özerk bir disiplin olarak kabul edilen çeviribilim, geçmişten günümüze edebiyat, psikoloji, sosyoloji, antropoloji ve tarih gibi pek çok sosyal bilim dalları ile etkileşime girdiği gibi başka alanları da etkilemiştir. Bu alanlardan biri de hiç kuşkusuz teknoloji olmuştur. 1980'li yıllarda teknolojinin gelişip değişmesi ile çeviribilim, yerelleştirme sektörünün ortaya çıkmasına aracılık etmiştir. 1990’l1 yıllarda sektörün gelişmesinin sonucunda çevirmenler büyük projelerde bilgisayar destekli çeviri araçlarından daha fazla faydalanmaya başlamıştır. Sektörün ilk ortaya çıktığı zamanlardan bu yana yerelleştirmenin çeviribilimin alt dalı olup olmadığına ilişkin tartışmalar devam etmektedir. Bazı kuramcılar, çeviri ve yerelleştirmenin benzer nitelikler taşıdığını savunmasına karşın, bazı kuramcılar iki alanın da çok farklı sürece ve işleyişe sahip olduğunu dile getirmektedir. Bu çalışmada, farklı kuramcıları görüşlerinden yola çıkarak yerelleştirme sürecini oluşturan küreselleştirme, uluslararasılaştırma, yerelleştirme aşamaları tanımlanıp çeviribilim ve yerelleştirme arasındaki ilişki ele alınmıştır. Bu bağlamda, bu ilişkiden yola çıkılarak ürünlerin hedef kitleye ulaştırılması için çağdaş çeviri kuramcısı Anthony Pym tarafından kullanılan aktarım ve dağıtım kavramlarının yerelleştirme sürecinde hangi açılardan ele alındığı ve bu kavramların nasıl nitelendirildiği tartışılmıştır. Makalede aynı zamanda Pym'in yaklaşımına dayanarak yerelleştirme olgusunda ve sürecinde çevirinin işleyişi ve yeri de irdelenmiștir.

Anahtar Sözcükler: Pym, Yerelleştirme, Uluslararasılaştırma, Küreselleştirme, Dă̆ıtım, Aktarım.

\section{Abstract \\ Functioning and place of translation in localization phenomenon and process from Anthony Pym's point of view}

Translation studies, which was accepted as an autonomous discipline in the 1970s, has not only interacted with many social sciences such as literature, psychology, sociology, anthropology, and history but also affected other fields. One of these fields has undoubtedly been technology. In the 1980s with the development and change of technology, translation studies mediated the emergence of the localization sector. As a result of the development of the sector in the 1990s, translators started to benefit more from computer-aided translation tools in large projects. Arguments about whether localization is a sub-branch of translation studies have been going on since the first emergence of the sector. Although some theorists argue that translation and localization have similar qualities, some theorists state that both fields have very different processes and operations. In this study, based on the views of different theorists, the stages of globalization, internationalization, localization that constitute the localization process are defined and 
the relation between translation studies and localization are discussed. In this context, based on this relation, it has been discussed from what angles the transfer and distribution concepts used by the contemporary translation theorist Anthony Pym to convey the outputs to the target audience in the localization process and how these concepts are defined. The article also examines the functioning and place of translation in the phenomenon and process of localization based on Pym's approach.

Keywords: Pym, Localization, Internationalization, Globalization, Distribution, Transfer. 


\section{EXTENDED ABSTRACT}

Translation studies expanded its scope by benefiting from different disciplines after it became an autonomous field in the 1970s. In the 1980s, the localization industry emerged with the expansion of the scope of translation studies and the development of technology. Translators started to take part in large projects using their personal computers and computer-aided tools with the change and development of technology in the 1990s. Scientists who have researched in both fields from past to present continue to discuss the relationship between translation and localization. Some argue that translation and localization processes are similar, while others state that the processes are very different from each other. Both the translation and localization relationship and the localization process, consisting of the stages of internationalization, globalization, and localization were examined within the scope of Anthony Pym's The Moving Text: Localization, translation and distribution by benefiting from the opinions of valuable academics and researchers. Although each concept is defined differently by scientists, the localization process, in general, can be summarized as adopting a product to the target language and preparing the product for use. In addition to the localization process, the transfer/distribution stage, in which the products in the localization process are delivered to the target audience, is also considered an important stage. The functions of the concepts of transfer and distribution, defined as two different concepts by Pym, in the localization process have been emphasized.

The first issue dealt with in the article is the localization process. It is useful to answer the questions such as what kind of processes are involved in localization and how this process works to understand the issue before questioning the transfer and distribution issues in the localization process in translation. Firstly, it is necessary to look at when the concepts of local, internationalization, and globalization, which are directly related to the phenomenon of localization, started to be used. Then, the relationship between translation studies and the localization industry is discussed. It can be said that the term translation is not a common concept under the localization approach, and it is one of the concepts that attract little attention in the localization industry. While there is a transfer from one language to another in translation, translation from one language to many languages is made in localization. The concepts of transfer and distribution are examined as part of the localization process after discussing the different and similar features of translation and localization.

Pym who emphasizes that transfer and translation are etymologically similar states that there are some differences between the two concepts. Although the concept of translation includes a narrow process that leads to a certain result, Pym sees the concept of transfer as the transfer of a product from another place and time to another place and time because of its physical movement. However, Pym claims that a text in the translation process is not obliged to act differently than transfer, and translators unwittingly reflect linguistic and cultural factors that depend on the source text to the translation processes. According to Pym, although translation and transfer refer to different phenomena and the two phenomena are interrelated processes, translation is dependent on transfer, whereas transfer does not depend on translation. Pym, who 
proposes to approach the phenomenon of localization not linguistically but historically and sociologically, argues that instead of looking at localization only from a linguistic perspective, it is necessary to examine localization from a broader perspective. Pym combining the concept of transfer with translation proposes the concept of distribution for localization. Pym explains the logic of distribution most plainly, by looking where the text and the words in the text go. Pym who considers distribution as a fluid cycle in continuous motion, argues that it is a necessity to create a distribution model. He has the opinion that each distribution is linked to other distributions and therefore affected by them. The point that should be underlined here is that distribution should not be considered equivalent to localization. He argues that although localization depends on the distribution, and they affect each other, distribution is not dependent on localization, distribution is possible even without localization. It can be said that distribution leads the localization approach within this framework. Therefore, distribution generally has priority as a precondition for the localization process. If nothing moved or was not moving, there would be no point in transforming texts either. The concepts of transfer and distribution are still discussed in the localization industry, which has changed over time. 


\section{Giriş}

Çeviribilim, yirminci yüzyılın ikinci yarısında dilbilimin ve edebiyat biliminin alt dalı olmaktan çıkıp özerk bir disiplin haline geldikten sonra farklı alanlardan yararlanıp kapsamını genişleterek disiplinlerarası çalışmalara açık bir alan olduğunu ortaya koymuştur. ${ }^{1}$ Özellikle 1970'li yıllarda disiplinlerarası bir bilim dalı olarak teknolojiden yararlanan çeviribilim ve çeviri uygulamaları alanında, başta çeviri bellekleri olmak üzere bilgisayar destekli çeviri gittikçe yaygınlaşmaya başlamıştır. 1980'li yıllarda teknolojinin daha da gelişmesi ile kişisel bilgisayarların üretimi, Schäler'in de vurguladığ 1 gibi yerelleştirme sektörünün ortaya çıkmasını sağlamıştır. 1990'lı yıllarda bu sektörde çalışmaya başlayan çevirmenlerin, ilk defa bilgisayar destekli çeviri araçlarını büyük projelerde kullanmaları artık kaçınılmaz olmuştur (2010: 209).

Günümüzde hala çok yeni olan yerelleştirme alanının, çeviribilimin alt dalı olup olmadığına ilişkin tartışmalar devam etmektedir. Bazı bilim insanları ve eleştirmenler, çeviri ve yerelleştirmenin benzer nitelikler taşıdığını savunsa da bazı araştırmacılar için söz konusu alanların birbirinden çok farklı sürece ve işleyişe sahip iki ayrı alan olduğu görüşündeler. Çeviride yerelleştirme olgusuna odaklanan çağdaş çeviri kuramcıları arasinda bulunan Anthony Pym, The Moving Text: Localization, translation and distribution adlı kitabında yerelleştirme sürecinde gerçekleşen aşamaları, uluslararasılaştırma, küreselleştirme, yerelleştirme ve dağıtım şeklinde tanımlamaktadır (2004: 29). Bu makalede, çeviri açısından yerelleştirme kavramı ve bunun bir parçası olan ürünlerin hedef kitleye ulaştırılma aşamasında dağıtımın ve aktarımın işlevi ve rolü Pym bağlamında sorgulanacaktır. Her iki kavramı farklı biçimde tanımlayan Pym, dağıtımdan ve aktarımdan ne anladığı, bunların yerelleştirme sürecinde hangi açılardan ele aldığı ve bu kavramları nasıl nitelendirdiği bu çalışmada irdelenip tartışılacaktır. Pym'in yerelleştirme sürecinde çeviri olgusunun işlev ve önemini nasıl yorumladığ kuramsal düzlemde bu makalede ortaya koymaya çalışırken, yaklaşım olarak yerelleştirme teknolojisinde kullanılan teknik söylemin hangi kavramlardan oluştuğu gösterilecektir. $\mathrm{Bu}$ çerçevede, yerelleştirme sürecini etkileyen küreselleşme ve uluslararasılaşma kavramlarının rolü, çeviri olgusu açısından betimlenecektir. Burada özellikle çeviride geleneksel anlamda bir ölçüt olarak görülen eşdeğerlilik kavramının neden geçerliliğini kaybettiği açıklanacaktır.

\section{Yerelleştirme Süreci}

Çevirideki yerelleştirme sürecinde aktarım ve dağıtım konularını sorgulamadan önce yerelleştirmede ne gibi süreçlerin bulunduğu ve bu sürecin nasıl işlediği gibi soruların yanıtlanmasında, konunun anlaşılması için yarar vardır. Öncelikle yerelleştirme

\footnotetext{
${ }^{1}$ Her ne kadar farklı alanlar tarafından, hatta çeviri ile uğraşan bilim insanları dahil olmak üzere bu sürecin hala devam ettiği tartışılsa da doksanlı yıllarda üniversitelerde çeviri hakkında araştırmaların ve yayınların artmasıyla birlikte bu alanda yayımlanan kuramsal kitaplar, çeviribiliminin özerk bir alan olarak kendini kabul ettiği görüşü benimsenmektedir. Ancak sosyal bilimlerdeki diğer alanlara oranla genç bir alan olan çeviribilim alan olarak kendi sınırlarını sorgulamaya devam etmektedir. Buna karşın günümüzde birçok alan için çeviribilim kuramsal bir alan olmaktan çok, edime diğer bir deyişle uygulamaya dayalı bir alan olarak görülmektedir.
} 
olgusuyla doğrudan bağlantılı olan yerel, uluslararasılaşma ve küreselleşme kavramlarının ne zaman kullanılmaya başlandığına bakmak gerekir. İlk kez, özellikle bir yerdeki duruma ya da bir ilişkiliye işaret eden yerel kavramı 1772 yılında, 'dışarıdan' gelen/aktarılan bir şeyi yerel yapmak ya da yerele doğru yönlendirmek anlamlarına gelen yerelleştirme kavramı 1792'de, bir şeyi yerellikten çıkararak, diğer bir deyişle belli bir ulusun ötesine taşınarak uluslararası düzeye ulaştırmak anlamında kullanılan uluslararasılaştırma kavramı 1864'de hayatımıza girmesine karşın, bir şeyin evrensel, yani küresel düzeyde yaygınlık ve geçerlilik kazanması anlamına gelen küreselleştirme kavramı 1944 yılında kullanılmaya başlanmıştır (Cadieux\&Esselink 2004). 18. ve 19. yüzyılda ilk kez kullanılan bu kavramlar, 20. yüzyılda ticaret, pazarlama ve piyasa olguların yaygınlaşmasıyla birlikte bazı anlam ve kapsam değişimine uğrayarak bir arada kullanılmaya başlanması gerek kendine özgü bir alan yaratmıştır gerekse çeviri olgusuyla farklı ve daha yoğun bir etkileşim içine girmiştir.

Genel anlamda bakıldığında, yerelleştirme süreci, uluslararasılaştırma, küreselleştirme ve yerelleştirme olmak üzere üç ana süreçten geçmektedir. Bu süreci daha iyi anlamak ve tartışmak için Yerelleştirme Endüstrisi Standartları Birliği (LISA) başta olmak üzere Esselink'in (2000), Pym'in (2004), Bengi-Öner'in (2006), Schäler'in (2008, 2010), Canım Alkan (2013) ve Odacığlu'nun (2016) bu kavramlara ve süreçlere ilişkin görüşleri burada irdelenecektir. Yerelleştirme Endüstrisi Standartları Birliği, uluslararasılaştırma kavramını, teknik düzeyde ürünü yerelleştirmek için uygun hale getirme işlemi olarak tanımlamaktadır. Bir başka deyişle, bir şey için yeniden tasarlama gerekmeksizin o şeyin hedef dile ve kültüre uyarlanmasını sağlayan bir işlem söz konusudur (LISA 2003: 14). Bu açıdan bakıldığında Pym, uluslararasılaştırma bir ürünü yeniden tasarlamaya gerek kalmadan birden çok dili ve kültürel gelenekleri işleyebilecek biçimde genelleştirme süreci olarak tanımlarken uluslararasılaştırma daha çok, program tasarımı ve belge geliştirme düzeyinde gerçekleştiğinin altını çizmektedir (2004: 29). Benzer bir görüşü savunan Schäler'e göre uluslararasılaştırma, yerelleştirilecek olan ürün içeriğinin çevri aşamasına hazırlanmasıdır. Bunun için bir ön hazırlık yapılması sonucunda dilsel/kültürel etmenlerde ortaya çıkabilecek olası sorunlar önlenerek dilsel/kültürel ögelerin uyarlanmasına olanak sağlanacaktır (2008: 196). İki kuramcının bu konuda görüşleri karşılaştırıldığında Pym, uluslararasılaştırma işlemini, ürünün genelleştirilmesi olarak tanımlarken, Schäler'in daha çok, ürünün hedef kitlenin dilsel ve kültürel ögelerin uyarlanmasına odaklandığı söylenebilir.

Yerelleştirme Endüstrisi Standartları Birliği'ne (LISA) göre küreselleştirme olgusu, yerel ve küresel bir ürünün çözümlenmesi ile başlayan, yerelleştirilmiş ürünler için destek ve geri bildirimler ile sona eren bir ürün geliştirme sürecinden oluşmaktadır (LISA 2003: 5). Ancak bu süreçte uluslararasılaştırmanın ve küreselleştirmenin konumu ve işleyişi konusunda kuramcılar arasında bazı görüş farklılıkları bulunmaktadır. Örneğin Odacıŏglu'na (2016) göre uluslararasılaştırma işleminin küreselleştirme işleminden önce gelmesi gerektiğini savunmasına karşın Pym'e (2004) ve Canım Alkan'a (2013) göre uluslararasılaştırma sonra gelmektedir. Bunun nedeni, Pym'in bu işlemi, küreselleştirme esnasında gerçekleşen işletme sorunlarının ele alındığı bir süreç olarak tanımlamasıdır. $\mathrm{Bu}$ süreci Pym, yüksek teknolojili ürünlerin uygun 
uluslararasılaştırma ve ürün tasarımının yanı sıra dünya pazarında pazarlama, satış ve desteğin ardından bir şirket genelinde yerelleştirilmesi olarak değerlendirmektedir (2004: 30). Konuyu biraz daha açımlayan Canım Alkan ise küreselleştirmeyi tanımlarken şu ayrımı yapmaktadır:

\begin{abstract}
İşletmelerin yerel pazarların sınırlarının dışına çıkmak ve ürün ve hizmetlerini küresel bir pazarda satın alınır hale getirmek için başvurdukları girişimlerin bütününe küreselleştirme denir. Küreselleştirme, satış ve pazarlama söyleminin ürettiği bir terimdir. İki ayaklı bir süreçtir. Bu sürecin bir ayağında uluslararasılaştırma diğer ayağında ise yerelleştirme yer alır. (2013: 21)
\end{abstract}

Stratejileri konusuna dikkat çeken Odacıoğlu ise, küreselleştirmeyi, "bir ürünü iç pazar dışında dış pazara da satmak isteyen şirketlerin bütün bir uluslararasılaştırma ve yerelleştirme aşamaları ile ilgili aldıkları ekonomik kararları ve bununla ilgili olarak geliştirdikleri stratejileri kapsamaktadır" (2016: 49) biçiminde tanımlamaktadır. Görüldüğü gibi, küreselleştirme tanımı, araştırmacılar arasında yorum farklılıkları bulunsa da üçünde de uluslararasılaştırma ve yerelleştirme işlemleri birbiriyle bağlantılı bir olguya ve sürece işaret etmektedir. Burada belirleyici olan işlemin asıl amacı, bir ürünün dünya çapında birden fazla hedef kitleye ulaştırılmasını sağlamaktır. Üçüncü ve son ana aşama olan yerelleştirme, Yerelleştirme Endüstrisi Standartları Birliği'ne (LISA), Pym'e ve Esselink'e göre bir ürünün alınmasını, kullanılacağı ve satılacağ1 hedef bölgeye (ülke/bölge ve dil) dilsel ve kültürel olarak uygun duruma getirilmesini kapsamaktadır (Esselink 2000: 3; LISA 2003: 13; Pym 2004: 29). Benzer bir görüşü savunan Bengi-Öner de yerelleştirmeyi "ana hatlarıyla yazılım ve ürünlerinin ulaşacağ kitleye göre kullanıma hazır hale getirilmesi". 2 Schäler ise yerelleştirmeyi, dijital içeriğin yabancı bir pazarın gereksinimlerine ve yerel ayarlarına dilbilimsel ve kültürel uyarlamasıdır olarak tanımlamaktadır (2010: 209). Genel olarak bakıldığında, yerelleştirme aşaması için bir ürünün uyarlanması ve kullanıma hazır hale getirme aşamasını kapsadığından, yerelleştirmede hedef kitlenin beklentileri, alışkanlıkları/gelenekleri ve değerleri göz önünde bulundurulmalıdır. Aksi taktirde, bir ürünün istenilen düzeyde hedef kitleye ulaşması ya da istenilen 'olumlu' etkiyi sağlaması güç olacaktır. Bu da doğal olarak yerelleştirmenin başarısız olduğu anlamına gelmektedir. Ancak burada yerelleştirme sürecinin tek başına belirleyici olduğunu söylemek de doğru değildir. Uluslararasılaştırma, küreselleştirme ve yerelleştirmenin dışında gelecek bölümde daha yakından irdelenecek olan aktarım ve dağıtım kavramları da yerelleştirmede önemli bir işleve sahiptir.

\title{
Çeviri ve Yerelleştirme
}

Çeviribilimin gelişiminde öncü bir role sahip olan James Holmes'un 1972 y1lında "Çevirinin Adı ve Doğası" (The Name and Nature of Translation Studies) adlı eseri ile söz konusu disiplinin sınırlarını, kapsamını ve özerkliğini bir yandan sorgularken, öte yandan çeviribiliminde edebiyat, psikoloji, tarih, dilbilim ve çeviri eğitimi gibi başka

\footnotetext{
${ }^{2}$ Işın Bengi-Öner, (2006). "Yerelleştirme"nin Tanımı. Çeviribilim. https://ceviribilim.com/2006/06/01/

$\%$ E2 \% 80\%9Cyerellestirme\%E2\%80\%9Dnin-tanimi/
} 
alanlara dolaylı ve dolaysız biçimde işaret ederek, alanın pek çok farklı disiplinler ile etkileşime girmesinin kaçınılmaz olduğunu ve bu nedenle disiplinlerarası bir bilim dalı niteliği taşıdığını vurgulamıştır. ${ }^{3}$ Snell-Hornby’nin bu bağlamda haklı olarak altını çizdiği gibi,

Holmes, yalnızca çeviri kuramcıları ve çevirmenler arasında değil aynı zamanda farklı bilim adamları ve okullar arasında özellikle -metin çalışmaları, dilbilim (başta psiko ve sosyo dilbilim olmak üzere), edebiyat, psikoloji, sosyoloji gibi disiplinlerarası bir takım çalışması şeklinde dayanışma çağrısında bulundu. (2006: 44)

Odacıoğlu ve Köktürk, "From Interdisciplinarity to Transdisciplinarity in the context of Technological Tools and Localization Industry" adlı makalelerinde çeviribilimin disiplinlerarası niteliğine işaret ederek çevirinin teknoloji ile etkileşime girmesi ile çeviribilim disiplinlerarasılıktan disiplinlerötesi bir bilim dalı haline getirdiğini savunmaktadırlar. Onlara göre bu terimin gündeme getirilmesindeki en büyük etken çeviribilimin sosyal bilimler dışında bir alan ile etkileşime girmiş olmasıdır (Odacıoğlu\&Köktürk 2015:15). Her ne kadar disiplinlerarası ilişkilerde etkileşimde iki alan olsa da Esselink (2000), Pym (2004), Bengi-Öner (2006) ve Schäler (2010) gibi kuramcılar yerelleştirmeyi ve çeviriyi birbirinde farklı iki süreç olarak tanımlayıp yerelleştirmenin dilsel öğelerin hedef kitleye ulaştırılmasının ötesinde gördükleri söylenebilir. Örneğin Pym'in The Moving Text: Localization, translation and distribution (2004) adlı eserinden yola çıkarak yerelleştirmenin salt kültürün ve dilin çevirisi olarak yorumlanamayacağını, bilgisayarların işletim sistemlerine kadar her şeyi kapsadığını öne sürebiliriz. Pym, bu bağlamda çevirinin yerelleştirmenin bir parçası olduğunu ve yerelleştirmenin her yerde olduğunu vurgulamaktadır. Çeviride metnin farklı bir dile çevrildiğini ve kaynak metnin hedef dilde temsil edildiğini belirten Pym, yerelleştirmede kaynak metnin değişmediği gibi, söz konusu metnin yanına diğer dillerden metinler eklendiğini dile getirmektedir. Bunun sonucunda bir kültürde üretilen metinler yerelleştirme sayesinde pek çok dile ve kültüre yayılmaktadır (2004: 2). Esselink, çeviri ve yerelleştirme arasındaki fark, çevirinin yerelleştirme faaliyetlerinden salt biri olmasıdır. ${ }^{5}$ Çünkü çeviriye ek olarak yerelleştirme projesi, proje yönetimi, yazılım mühendisliği, test etme ve masaüstü yayıncılık gibi birçok görevi içermektedir (2000: 4). Pym de çeviri ve yerelleştirme arasındaki farkı vurgulayarak yerelleştirmede

\footnotetext{
${ }^{3}$ Holmes'un çeviribilim alanında ilk kez yapmış olduğu çeviri haritası, disiplin olarak çeviribilimin çalışma alanlarına göre akademik anlamda irdelemesi açısından önemlidir. Munday’ın belirttiği gibi, çevirinin bilimselleşme süreci başlamadan önce çeviri bir dil öğrenme yöntemi olarak ya da karşılaştırmalı edebiyatın, çeviri atölyelerinin ve karşılaştırmalı dilbilim kurslarının bir parçası olarak görülürken, yeni disipline Holmes'un bir isim ve bir yap1 önermesi açısından ona çok şey borçludur (2001: 17). Pym, Holmes Haritası'nda bulunan bazı eksikliklere işaret ederek, söz konusu haritanın bazı ilgi alanları dışladığını ve artık güncelliğini kaybederek güvenilir bir rehber olamayacağını çünkü bu tür haritaların sosyal açıdan önemli konuları ele almayı başaramazsa, yok olmayı ve akademik müzelere kaldırılacağı ve bu nedenle haritaların bizi belirli yönlere bakmaya yönlendirmesine karşın başka yönlere bakmamızı engelleyen garip güç araçlar olduğu için eleştirmektedir (Pym 1998: 2-3).

4 Çevrilmemiş bir kaynak metnin doğrudan çevirisini ilk kez burada kullanacaksanız bunu bir dipnotla belirtmek gerekir. Örneğin, çalışmada kullanılan ve Türkçe çevrilmemiş olan İngilizce kaynaklardan yapılan doğrudan alıntılar tarafımdan yapılmıştır.

5 Esselink'e göre çeviri, yazılı metni ya da sözlü ifadeleri başka bir dile dönüştürme işlemi olduğundan dolayı çevirmenin kültürel farkların ve üslubun korunmasına dikkat ederek kaynak metnin anlamını hedef dile doğru bir biçimde aktarması gerekmektedir (2000: 4).
} 
yeniden tasarım ve adaptasyon gibi işlemler gerçekleşirken çeviride, erek dile uygun eşdeğerliğin sağlandığ 1 bir metin değişim sürecine girmektedir (2004: 54). Bunun yanında, yerelleştirme sürecinde önemli bir rol oynayan uluslararasılaştırma süreci, çeviride etkili bir eşdeğerliliği amaçlamaktadır. ${ }^{6}$ Ancak, tam anlamıyla uluslararasılaşma gerçekleşirse çeviri ilgi çekmeyen, salt bir dil sorununa indirgenen ve eşitlik sağlayan otomatik bir sürece dönüşmektedir. Çünkü çeviride eşdeğerlik sağlamada uluslararasılaşma yetersiz kalmaktadır. Nida'nın devingen eşdeğerlik kuramından yola çıkarak Pym, bir metnin başka bir dilde ve kültüre bağlı olarak değişiklik gösterebileceğini ve metin farklı bir biçime girerek aynı anlama ulaşabileceğini düşünmektedir (a.g.e.). Eşdeğerlik, her ne kadar kaynak ve hedef metin ilişkisini gösterse de eşdeğerliliğin niteliği hedef metne yansıdığından dolayı Pym, eşdeğerlik kavramının tek yönlü olduğunu kanısındadır (a.g.e.: 62).

Genel olarak yorumlandığından çeviri teriminin yerelleştirme yaklaşımı altında pek görülen bir kavram olmadığını ve yerelleştirme sektöründe çok az ilgi çeken kavramlardan biri olduğu söylenebilir. Çeviride bir dilden başka bir dile aktarım söz konusuyken, yerelleştirmede bir dilden birçok dile çeviri yapılmaktadır. Benzer biçimde, çeviride süreç, tek yönlü ve asimetrik gerçekleşirken, yerelleştirmede metinler karş1lıklı olarak birbirine eşdeğer ve simetrik konumda bulunmaktadır. Bundan dolayı Pym, çeviride her zaman üçüncü bir problemin ortaya çıkabileceğini ancak uluslararasılaştırma sürecinde sorunların çok daha belirgin olacağını öne sürmektedir (a.g.e.: 63). Ona göre çeviride metinler daha doğal ve değişken olabiliyorken, yerelleştirilen ürünler sabit ve yapaydır. Bu nedenle, çeviride dilsel sorunlar daha ön plandayken yerelleştirmede dilin dışında kaynaklanan farklı sorunlar gündeme gelmektedir (a.g.e.: 51).

\section{Yerelleştirmede Aktarım ve Dağıtım Sorgulaması}

Pym, yerelleştirme kuramı için 1992 y1lında Translation and Text Transfer adlı eserinde aktarım (transfer) kavramını kullanırken 2004 yılında eserini gözden geçirip The Moving Text: Localization, Translation and Distribution adlı eserinde dağıtım (distribution) kavramını tercih ettiği görülmektedir. Kavram değişikliğine gitmesinin kaynağında, metnin ve metnin içinde kullanılan sözcüklerin nasıl değişime uğradığı ile ilgili olduğunu ikinci kitabında dile getirmektedir. İki kavram arasındaki fark1 yorumladığımızda, aktarımın daha çok bir yer değiştirmeye gönderme yapmasına karşın, dağıtımın ise bir şeyin farklı hedeflere ulaştırılması söz konusu olduğu söylenebilir. Dolayısıyla birinci kavram, bir yöne doğru bir eylem ve bir çıkış noktasına işaret ederken, ikinci kavramda farklı yönlere doğru olan eylemlere ve ulaşılmak istenen

\footnotetext{
${ }^{6}$ Bu bağlamda, çeviribilimin babası olarak görülen Amerikalı dilbilimci Eugene A. Nida, eşdeğerliliğgi devingen ve biçimsel olmak üzere ikiye ayırarak İncil'in özellikle Batı anlayışına ve kültürüne uzak olan daha 'küçük' dilleri konuşan kültüre yönelik yapılan çevirilerde yerelleştirici çeviri yaklaşımı yansıtan devingen eşdeğerliliğin benimsenmesi gerektiği görüşündedir. Ona göre erek okur odaklı olan bu eşdeğerliliğin sağlanmasıyla istenilen mesajın aktarılması için dilin kutsallığı yerine metindeki mesajın en etkili biçimde erek kültüre uyarlanması, başka bir deyişle yerelleştirilmesi gerekmektedir (Nida 1981: 125).
} 
hedeflere yönelik bir eylem ön plana çıkmaktadır. Pym'in böyle bir ayrıma gitmesinin bir nedeni de, çevirinin özellikle dilbilimsel bir yaklaşım bağlamında aktarım olarak görülmesidir. $\mathrm{Bu}$ yaklaşım daha çok kaynak odaklı bir anlayışı yansıtmasına karşın, yerelleştirmeye ve bundan dolayı erek odaklılığa işaret eden dağıtım daha uygun bir kavram olarak yorumlanmış olabilir. Pym'in de altını çizdiği gibi, birçok kuramcı için çeviri bir anlam aktarımı olarak nitelendirilmektedir (2004: 12). Bu açıdan bakıldığında, Pym'in bir taraftan geleneksek çeviri kavramına karşı gelirken, öte taraftan çeviride anlam odaklı bir anlayışı benimsemediğini dolaylı olarak vurguladığı sonucuna varılabilir. Çünkü çevirinin salt tek düzlemli olan anlam aktarımından çok, birçok etmeni içinde barındıran karmaşık ve değişken bir olgu olduğu birçok çeviri bilimci tarafından kabul edilmektedir. Yerelleştirme doğası gereği, yerel norm ve değerlere göre biçimlendirildiğinden dolayı, yerelleştirmede kaynak odaklı bir anlayışın geçerliliği söz konusu değildir.

Aktarım kavramını irdeleyen kuramcılardan Susanne Göpferich'e göre aktarım çeviriden farklı olduğu gibi kavramın kapsam olarak da daha geniş bir anlamı vardır. Aktarım yapılırken üretilen metin ve araçlar göreceli olarak değişebilirken, çeviri olgusunda ise daha çok, metnin anlamsal içeriği hedef kitleye ulaştırılmaktadır (2010: 374). Etimolojik olarak aktarım ve çeviri kavramlarını karşılaştıran Pym buna karşın, bu kavramların aynı kökten geldiğine işaret etmektedir. Bunun en somut kanıtı, İngilizce "translation" kavramının Latince "translatus" kavramının geçmiş zaman eki almış hali "transferre" sözcüğünden türetilmiş olmasıdır (1992: 16). Buna karşın, iki kavram arasında bazı farklılıkların bulunduğunu savunan Pym, çeviri kavramını belli bir sonuca yönelen dar bir süreci kapsamasına karşın, aktarım kavramı ile bir ürünün başka bir yer ve zamandan fiziksel olarak hareket etmesi sonucu başka bir yer ve zamana aktarılması olarak görmektedir (a.g.e.). Oysa aktarımdan farklı olarak çeviride bir metnin hareket etme zorunluluğunun bulunmadığını öne süren Pym, çevirmenler farkında olmadan kaynak metne bağlı olan dilbilimsel ve kültürel etmenleri çeviri süreçlerine yansıtmaktadırlar. Her ne kadar çeviri ve aktarım birbirinden farklı olgulara işaret etseler de, Pym'e göre iki olgu birbiriyle bağlantılı süreçler olmakla birlikte, çevirinin aktarıma bağlı, buna karşın aktarım ise çeviriye bağlı değildir (a.g.e.: 17). Aktarım kavramının zaman içinde konsept karmaşasına yol açtı̆̆ını dile getiren Pym, EvenZohar'ın dışarıdan alım (importation) ve aktarım (transfer) kavramlarından yola çıkarak dağıtım kavramının yerelleştirme için daha uygun bir kavram olacağını dile getirmiştir (2004: 14). Even-Zohar'a göre içerik üretimi dışarıdan alım aracılığı ile gerçekleşebilmektedir (2003: 428). Pym, Even-Zohar'ın aktarım kavramının kültürel ögelerin madde halinde fiziksel olarak hareket etmesi anlamına gelen dişarıdan alım kavramına denk geldiğini dile getirmiştir (2004: 13). Aktarım kavramını Pym, EvenZohar'dan farklı bir açıdan değerlendirerek aktarım kavramının zamanda ve mekandaki harekete işaret ettiğini vurgulayarak aktarımın üründe herhangi bir değişiklik getirmekten çok, ürünün konum değiştirmesiyle ilintili olduğunu belirtmektedir (2004: 13-14). Bu açıdan bakıldığında, Pym'in aktarımda ürünün içeriğini ve işlevini koruyarak aynı içerik ve işlevi aktarılacak üründe yapılacak bir değişimi onaylamadığı söylenebilir. Yerelleştirme bağlamında değerlendirildiğinde bir ürün olan metin, erek 
kültüre yabancılaştırılmadan aktarılması gerektiği ileri sürülebilir. Başka bir deyişle, erek "tüketici" ya da alımlayıcı ürünün dışarından bir alım olduğunu duyumsamamalıdır.

Pym, metnin ve metin içindeki kelimelerin nereye gittiğine bakarak, en yalın biçimde dağıtımın mantığını şu şekilde anlatmaktadır. Yerelleştirme yapmak isteyen şirket/kuruluş dağıtım için yeni yerel işletmeler bulmak ya da daha önceden çalışılan işletmelerin alanlarını genişletmek gerektiğini belirtmektedir. Dağıtımın sürekli hareket halinde akışkan bir döngü olarak gören Pym, dağıtım modelinin oluşturulmasının bir zorunluluk olduğunu savunmaktadır. Uygun bir model oluşturulmadığı takdirde döngü kısalır, zayıflar ve metin işlevselliğini kaybetmeye başlar. Dağıtımdan kaynaklanan hareketlilik, ürünü tanıtarak, zincirlere dağıtım, güncelleme ya da yerelde geçerli olan normlara uyarak sağlanabilir (2004: 6).

Yerelleştirme olgusuna dilbilimsel olarak değil, tarihi ve sosyolojik açıdan yaklaşılmasını öneren Pym, yerelleştirmeye salt dilsel açıdan bakmak yerine yerelleştirmeyi daha geniş bir açıdan irdelemek gerektiğini savunmaktadır. Pym'e göre dilbilimsel modeller, mekân ve zaman arasında köprü işlevi taşıyan dağıtım anlayışı, istenilen başarıyı sağlayamamıştır. Bunun yanında, yerelleştirmenin jeopolitik bir niteliğe işaret etmediğini, yerelleştirmeyle dünyanın dört bir yanına dağıtım yapılabileceğini dile getirerek (a.g.e.: 22) işaretlerden yazılı metinlere kadar dağıtılan her şeyin metin olarak kabul edildiğini öne sürmektedir. Pym, her dağıtımın başka dağıtımlarla bağlantı içerisinde olduğu, dolayısıyla onlardan da etkilendiği görüşündedir. Burada altı çizilmesi gereken konu, dağıtımın yerelleştirmeyle eşdeğer olarak değerlendirilmemesi gerektiğidir. Her ne kadar birbirini etkiseler de yerelleştirmenin dağıtıma bağlı olmasına karşın dağıtımın yerelleştirmeye bağlı olmadığını öne süren Pym, yerelleştirme olmasa bile dağıtımın mümkün olduğunu savunmaktadır (a.g.e.: 15). Bu çerçeve içerisinde bakıldığında, dağıtımın yerelleştirme anlayışına öncülük ettiği söylenebilir. Dolayısıyla dağıtım, yerelleştirme uygulamasının bir ön koşulu olarak genel anlamda bir önceliğe sahiptir. Hiçbir şey hareket etmediyse ya da hareket etmeyecekse, metinleri dönüştürmenin de bir amacı olmazdı. Pym'in haklı olarak altını çizdiği gibi, bir şey yerelleştiriliyorsa ya da yerelleştirmişse, o şey bir yerden başka bir yere taşınmıştır ya da taşınması amaçlanmıştır (a.g.e.: 16). Pym burada bir anlamda taşınmanın/dağıtımın yeni bir ortama uyum sağlamak ya da yerel normları benimsemek için yerelleşmenin hedef kitle açısından bakıldığında en uygun yol olduğunu ancak bunun tek yol olmadığını vurgulamaktadır. Çünkü dağıtımın nasıl sonuç vereceği ya da ürünün nasıl alımlanacağı toplumda egemen olan başka etmenlere de bağlıdır.

\section{Sonuç}

1970'li yıllarda çeviribilim özerk bir alan olma görüşü tartışılmaya başlandıktan sonra farklı bilim dallarından faydalanarak kapsamını genişletmiştir. 1980'li yıllarda çeviribilimin kapsamının çeşitlenmesi ve teknolojinin ilerlemesi ile yerelleştirme endüstrisi ortaya çıkmıştır. 1990'lı yıllarda teknolojinin değişip gelişmesi ile 
çevirmenler bilgisayar destekli araçları kullanarak büyük projelerde yer almaya başlamıştır. Her iki alanda da araştırmalar yapan bilim insanları çeviri ve yerelleştirme arasındaki ilişkiyi sorgulamaya ve geliştirmeye devam etmektedir. Bazı kuramcılar, çeviri ve yerelleştirme süreçlerinin birbirine benzediğini savunurken, bazıları buna karşı gelerek iki alandaki süreçlerin birbirinden çok farklı olduğunu dile getirmiştir. Çalışmamızda, gerek çeviri ve yerelleştirme ilişkisi, gerekse yerelleştirme süreci, uluslararasılaştırma, küreselleştirme ve yerelleştirme aşamaları Anthony Pym'in bakış açısı bağlamında irdelenmiştir. Her ne kadar bu kavramlar kuramcılar tarafindan farklı tanımlanmış olsa da, genel olarak yerelleştirme süreci bir ürünün hedef dile uyarlanması ve ürünün kullanılmaya hazırlanması olarak özetlenebilir. Çeviride olduğu gibi yerelleştirme sürecinde de hedef kitlenin beklentileri, alışkanlıkları, gelenekleri ve değerleri göz önünde bulundurulması gerektiği vurgulanmıştır. Aksi halde, bir ürünün hedef kitleye ulaşmasında ve anlaşılmasında bazı sorunlar ortaya çıkması kaçınılmaz olacaktır. Bu da yerelleştirme işlemini başarısız kılacaktır.

Makalede gösterildiği gibi, yerelleştirme süreci içerisinde bulunan ürünlerin hedef kitleye ulaştırılmasını sağlayan aktarım/dağıtım aşaması önemli bir yere sahiptir. Bu bağlamda, Pym tarafindan farklı iki kavram olarak tanımlanan aktarım ve dağıtım kavramlarının yerelleştirme sürecindeki işlevleri üzerinde durulmuştur. Pym, on iki y1l önce yapmış olduğu çalışmasında kullandığı aktarım kavramı yerine 2004 yılında değiştirerek dağıtım kavramını kullanmaya başlamıştır. İki kavram arasındaki farkı sorgulayan Pym, aktarımın, yer değiştirme, buna karşın dağıtımı, bir ürünün farklı hedef kitlelere iletilmesi olarak tanımlamıştır. İki kavram arasındaki farkın altını çizen Pym, aktarımda tek bir yöne doğru gerçekleşen bir eylem söz konusuyken, dağıtımda farklı yönlere aynı anda gerçekleştirilebilecek bir eyleme işaret etmektedir. Pym'in yerelleştirme açısından belirleyici olan kavram konusunda değişikliğe gitmesinin nedeni, dilbilimcilerin çeviriyi aktarım olarak görmesine bağlanabilir. Pym, yerelleştirme sürecini dilbilimsel yaklaşımın dışına çıkartarak kapsamını bir anlamda genişletip sosyolojik ve tarihi açllardan değerlendirilmesi gerektiği görüşünü savunmaktadır. Benzer bir görüşü, kaynak odaklı bir yaklaşımı yansıtan aktarım kavramı yerine Pym, yerelleştirme sektörü için daha uygun olduğunu düşündüğü hedef kitle odaklı dağıtım kavramını ön plana çıkarmıştır. Bu açıdan bakıldığında, belli bir alan içerisinden kullanılan bazı kavramların zaman içerisinde değişime uğrayarak aynı kuramcılar tarafından değiştirilebilmesi, söz konusu aktarım ve dağıtım kavramlarının yerelleştirme sektöründe tartışılmaya devam edeceğinin göstergesidir. Seksenli yıllardan itibaren bilimsel kimliğini sorgulamaya başlayan çeviribilimin görece olarak genç bir alan olması nedeniyle bazı kavramların sorgulanması ve değişime uğraması kaçınılmaz bir olgudur.

\section{Kaynakça}

Bengi-Öner, Işın (2006): “Yerelleştirme”nin Tanımı. https://ceviribilim.com/2006/06/01/\%E2\%80\%9 Cyerellestirme\%E2\%80\%9Dnin-tanimi/ (Son erişim tarihi: 03.03.2021). 
Cadieux, Pierre/ Bert Esselink (2004): GILT: Globalization, Internationalization, Localization, Translation. https://www.translationdirectory.com/article127.htm (Son erişim tarihi: 24.02.2021).

Canım Alkan, Sinem (2008): Türkiye'de Çeviri Bürolarında Web Sitesi Yerelleştirmeleri ve Bu Süreçte Bilgi Teknolojilerinin Kullanımı. Yayımlanmamış yüksek lisans tezi, İstanbul Üniversitesi, Sosyal Bilimler Enstitüsü, Çeviribilim Anabilim Dalı.

Canım Alkan, Sinem (2013): Web Sitesi Yerelleştirmelerinde Bir Eyleyen olarak Çevirmenin Konumu: Türkiye Örneği. Yayımlanmamış doktora tezi, İstanbul Üniversitesi, Sosyal Bilimler Enstitüsü, Çeviribilim Anabilim Dalı.

Esselink, Bert (2000): A Practical Guide to Localization. John Benjamins Publishing Co.

Even-Zohar, Itamar (2003): The Making of Cultural Repertoire and the Role of Transfer. Translation Translation. Amsterdam ve New York: Rodopi, 425-431.

Göpferich, Susanne (2010): Transfer and Transfer Studies. Gambier, Yves/ van Doorslaer, Luc (Ed.): Handbook of Translation Studies. Amsterdam: John Benjamins Publishing Co., 374-377.

Holmes, James S. (2004): Çeviribilimin Adı ve Doğası. Rıfat, Mehmet (Ed.): Çeviri(bilim) nedir? İstanbul: Dünya, 165-182.

LISA (2003): The Localization Industry Primer. İkinci Baskı. İsviçre: SMP\&LISA.

Munday, Jeremy (2001): Introducing Translation Studies. London: Routledge.

Nida, Eugene A. (1981): Das Wesen des Übersetzens [1975]. Übersetzungswissenschaft. Wolfram Wilss (Ed.). Darmstadt: Klett, 123-147.

Odacioğlu, Mehmet Cem \& Şaban Köktürk (2015): From Interdisciplinarity to Transdisciplinarity in Translation Studies in the Context of Technological Tools \& Localization Industry. International Journal of Comparative Literature \& Translation Studies. 3 (3), 14-19.

Odacıŏlu, Mehmet Cem (2016): Çeviribilimde Yerelleştirme Paradigmasına Doğru. Yayımlanmamış doktora tezi, Sakarya Üniversitesi, Sosyal Bilimler Enstitüsü, Çeviribilim Anabilim Dalı.

Pym, Anthony (1998): Method in Translation History. Manchester: St. Jerome Publishing.

Pym, Anthony (1992): Translation and Text Transfer. Frankfurt am Main: Peter Lang.

Pym, Anthony (2004): The Moving Text: Localization, Translation and Distribution. Amsterdan/ Philadelphia: John Benjamins Publishing Company.

Pym, Anthony (2004): Localization from the Perspective of Translation Studies: Ovelaps in Digital Divide?https://www.researchgate.net/publication/250363090_Localization_from_the_Perspective_ of_Translation_Studies_Overlaps_in_the_Digital_Divide (Son erişim tarihi: $10 . \overline{2} .2021$ ).

Pym, Anthony (2005): Localization: On its nature, virtues and dangers. https://core.ac.uk/download/pdf/52135437.pdf (Son erişim tarihi: 02.03.2021).

Pym, Anthony (2006): What Localization Models Can Learn From Translation Theory. https://usuaris.tinet.cat/apym/on-line/translation/localization_translation_theory.pdf (Son erişim tarihi: 14.03.2021).

Schäler, Reinhard (2010): Localization and translation. Handbook of Translation Studies. Amsterdam: John Benjamins Publishing Co., 209-214.

Snell-Hornby, Mary (2006): The Turns of Translation Studies. Amsterdam/Philadelphia: John Benjamins B.V. 